\title{
Peri-implantitis in the esthetic zone: a guideline for decision making and treatment modalities
}

\author{
Dennis P. Tarnow ${ }^{1}$, Stephanie M. Chu ${ }^{2}$, Stephen J. Chu ${ }^{3}$ \\ ${ }^{1}$ Education in Implant Dentistry, Columbia University College of Dental Medicine, Private Practice, New York, NY, USA; ${ }^{2}$ Private Practice, New \\ York, NY, USA; ${ }^{3}$ Ashman Department of Periodontology and Implant Dentistry, Department of Prosthodontics, New York University College of \\ Dentistry, Private Practice, New York, NY, USA \\ Correspondence to: Dennis P. Tarnow, DDS. Education in Implant Dentistry, Columbia University College of Dental Medicine, Private Practice, 150 \\ East 58th Street, Ste. 3200, New York, NY 10155, USA. Email: dennistarnow@gmail.com.
}

\begin{abstract}
A clinical case series is presented in this practice guideline review that identifies the various types of peri-implantitis defects in the esthetic zone along with their therapeutic management. Remediation of problems in the esthetic zone requires meticulous attention to preserving the pre-existing esthetics and the employment of biologically-sound surgical approaches that allow for such, all while resolving the underlying disease. The aim of this report is to provide a clinically-oriented guideline for the clinician who is often faced with treating such complex problems. Diagnosing and identifying the various factors that may influence the clinical end result is critical. There are three possible scenarios of peri-implantitis in the esthetic zone, categorized dependent upon the absence or presence of bone loss or soft tissue loss. The first scenario consists of a peri-implant soft tissue deformity with no accompanying bone loss; the second, a peri-implant hard tissue defect with no soft tissue loss; and the third describes a combination of both hard and soft tissue loss. In addition to elaborating on these different scenarios, this report will explain the biologically- and prosthetically-based decision making process and treatment modalities for each and demonstrate via a case series the clinical management of such defects.
\end{abstract}

Keywords: Peri-implantitis; esthetics; interdisciplinary management; soft tissue; guided bone regeneration

Received: 30 April 2021; Accepted: 21 July 2021; Published: 10 September 2021.

doi: $10.21037 /$ fomm-21-59

View this article at: https://dx.doi.org/10.21037/fomm-21-59

\section{Introduction}

The prevalence of dental implants, that is to say, the number of individuals who have at least one dental implant among those with at least one missing tooth, in the US has exponentially been increasing throughout the decades; a recent NHANES analysis reported that the prevalence of dental implants jumped from $0.7 \%$ in 1999 to $5.7 \%$ in 2015 . In fact, this number could increase to $23 \%$ by 2026 (1). As the prevalence of implants increases, so too does that of peri-implantitis, which has been reported to range from $5.9-45 \%$ depending on the case definition (2,3). A standardized definition of peri-implantitis has recently been put forth in a joint World Workshop by the Academy of Periodontology and the European Federation of Periodontology. It is characterized by the presence of peri- implant signs of inflammation, radiographic evidence of bone loss following initial healing, or increasing probing depth as compared to probing depth values collected after placement of the prosthetic construction. In the absence of prior radiographs and clinical data, it is defined as radiographic bone level loss of $3+\mathrm{mm}$ from the top of the implant, in combination with profuse bleeding and/or suppuration, and probing depths of $6+\mathrm{mm}$ (4).

As the prevalence of peri-implant disease increases, the clinician is faced with treating these areas more frequently than ever. Particularly in situations of peri-implantitis in the esthetic zone, one is often-times faced with the dilemma of treating the peri-implant infection at the expense of a compromised esthetic outcome. This article will specifically present the three possible case scenarios 


\begin{tabular}{lll}
\hline $\begin{array}{l}\text { Recession } \\
\text { (mid-facial or } \\
\text { interproximal) }\end{array}$ & $\begin{array}{c}\text { Bone } \\
\text { loss }\end{array}$ & Therapy \\
\hline+ & - & $\begin{array}{l}\text { (I) Decoronate } \\
\text { (II) Soft tissue graft }\end{array}$ \\
& & (III) Coronally positioned flap \\
\hline- & (I) Hard +/- soft tissue graft \\
& (II) Flap replacement \\
\hline+ & (I) Explant \\
& (II) Site development for future \\
& implant replacement \\
& (III) Implant placement
\end{tabular}

$\overline{\text { Figure } 1 \text { Decision making table for treatment modalities. +, }}$ presence; -, absence.

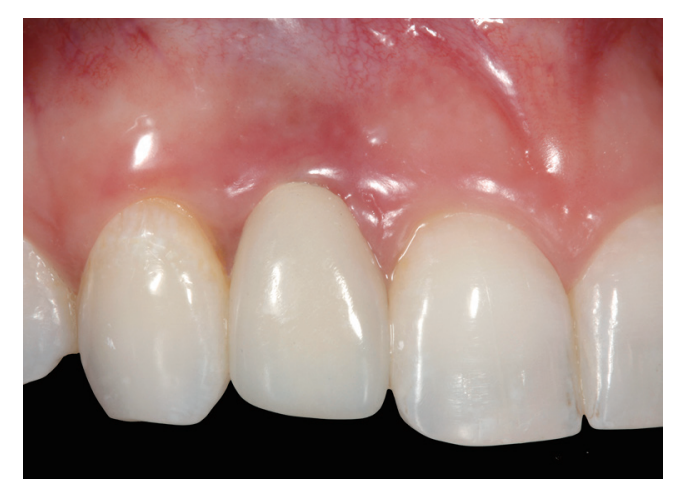

Figure 2 Note inflammation of the peri-implant tissues and midfacial recession at site \#7.

of peri-implantitis in the smile zone, guide the clinician in how to address the management in an estheticallyoriented and evidence-based manner, and provide indications on when to remove the problem implant. We present the following article in accordance with the RIGHT reporting checklist (available at https://fomm. amegroups.com/article/view/10.21037/fomm-21-59/rc).

\section{Three peri-implantitis scenarios in the esthetic zone}

There are three main clinical scenarios of peri-implantitis in the esthetic zone, as outlined in Figure 1. They are defined by the absence or presence of a soft tissue deformity and/ or peri-implant bone loss and as such, warrant different treatment approaches. The first such Case scenario \#1 illustrates the presence of a soft tissue esthetic deformity but no accompanying peri-implant bone loss.

\section{Case scenario \#1}

Description of problem: an implant with an esthetic deformity and peri-implant mucositis due to excessive labial spatial placement, causing facial recession. This scenario has healthy peri-implant bone levels, with only a soft tissue defect. See Figure 2.

Abbreviated Solution: Debridement and decoronation (5) of the implant followed a period of healing of three-four weeks for complete soft tissue closure. The implant is then decontaminated and augmented with soft tissue grafting via a papillae-sparing incision and the flap is coronally repositioned. After a period of connective tissue maturation of three months, the implant is then uncovered and provisionalized with a flat healing abutment or emergence profile. After maturation of the soft tissues, the definitive restoration may be delivered with flat subgingival contours to allow for soft tissue stability long-term (6-8).

The following case report demonstrates this type of scenario: a 28 year-old Caucasian female presented with her implant in tooth \#7 position significantly longer than natural tooth \#10 and was dissatisfied with the esthetics of the crown and the soft tissue discoloration (Figure 2). The existing implant was ten years old but had a healthy bone level (Figure 3). The esthetic deformity was due to the excessive facial positioning of the fixture with accompanying peri-implant mucositis (Figure 4). The implant was decontaminated and decoronated with the placement of a cover screw and the gingiva was allowed to proliferate in situ (5) for a period of 2-4 weeks while the area was provisionalized with a resin bonded Maryland bridge (Figures 5-7). The authors have observed that the gingiva never fully closes over the cover screw due to residual inflammation from plaque trapping within the hex of the cover screw. The area was then augmented with a CTG via a papillae-sparing mid-crestal incision design and allowed to mature for three months completely submerged (Figures 8-10). Then the implant was uncovered, again with papillae-sparing incisions, with the insertion of a flat contoured healing abutment as to preserve the newly corrected soft tissue profile (Figure 11). Four to six weeks later, an implantsupported provisional with flat facial contours was inserted to maintain the new gingival margin height (Figure 12), followed by definitive prosthesis delivery $(7,8)$. The custom abutment was gold-plated ceramo-metal, allowing for 


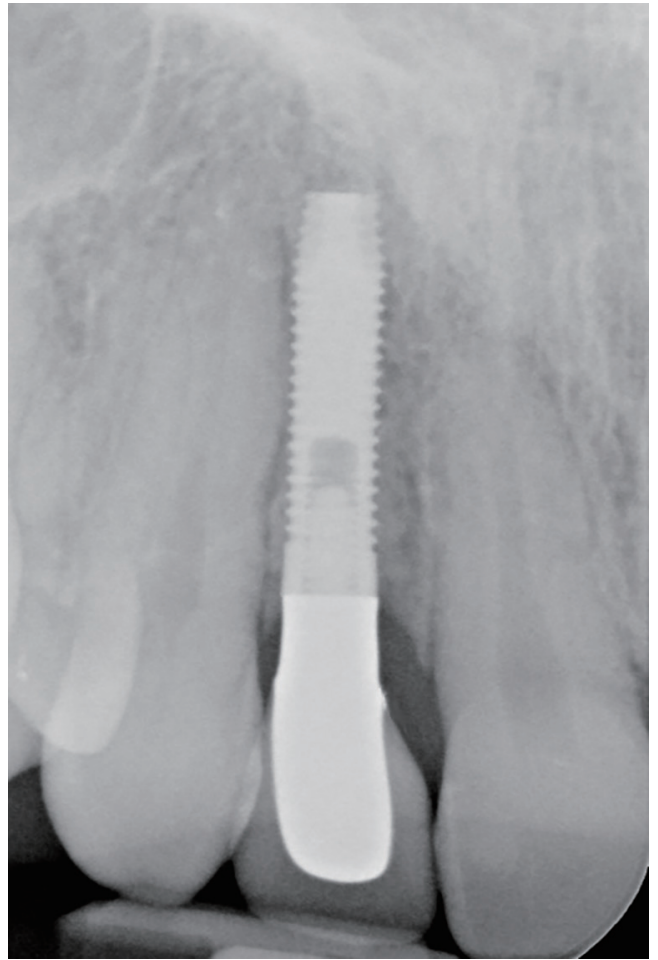

Figure 3 Note healthy peri-implant bone levels.

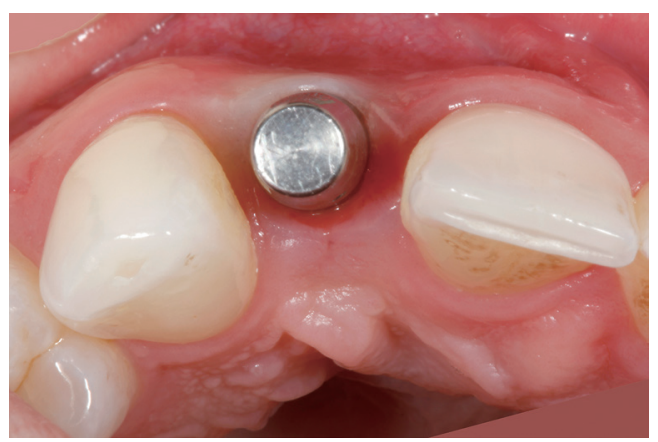

Figure 4 Note severe labial angulation.

greater strength than a zirconia abutment (Figure 13). Recall at five years shows excellent tissue stability and greatly improved soft tissue profile (Figure 14). Although the implant originally placed was too facial, a crucial factor is that it was healthy without any peri-implant disease and was positioned deep enough to allow for angle correction and coverage with a soft tissue augmentation procedure.

\section{Incision design}

A papillae-sparing incision design has been described (9) as a

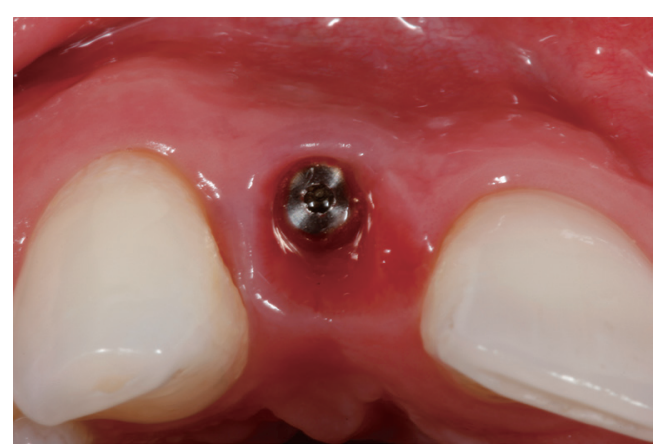

Figure 5 A cover screw is placed and the implant is decoronated.

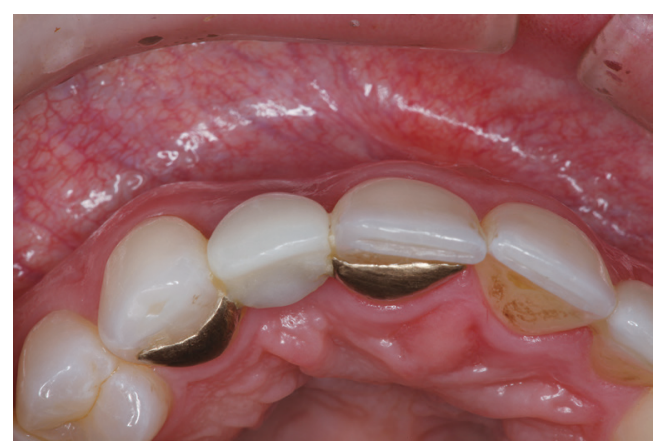

Figure 6 A spot-etched bonded bridge is utilized as a provisional at sites \#6-8.

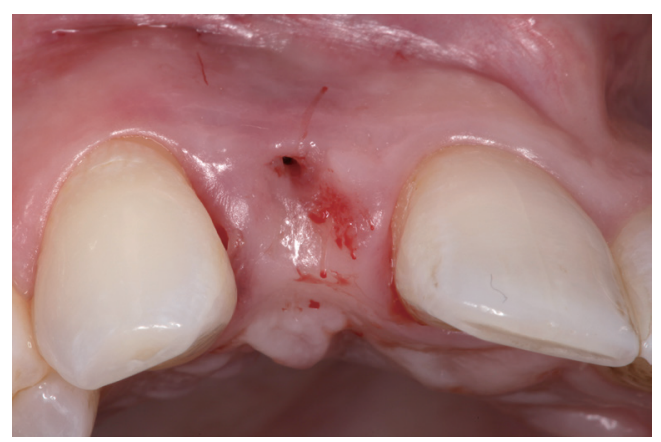

Figure 7 After a period of three weeks submerged, the implant has been almost completely covered with keratinized tissue. A small fistula is present over the hex of the cover screw where plaque collects, preventing complete closure.

horizontal incision over the mid-crest of the ridge, stopping short of about $1 \mathrm{~mm}$ of the papillary tissues. The flap design then extends buccally with bilateral vertical releasing incisions that diverge broadly to allow for maximum vascularization from the base of the pedicle. These vertical 


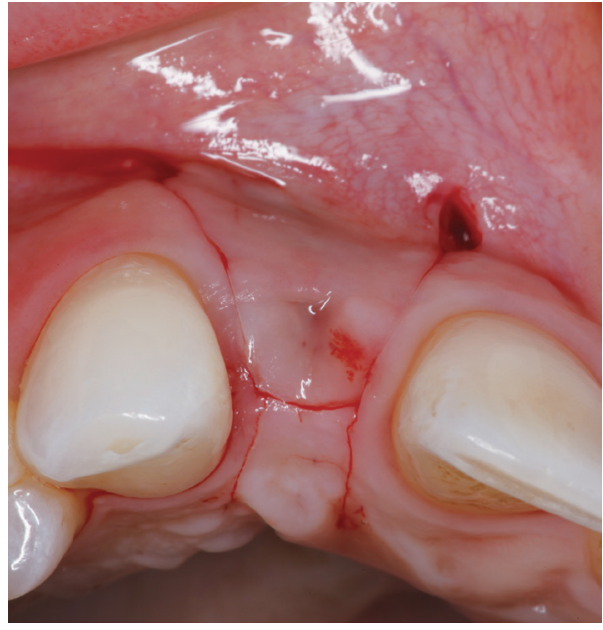

Figure 8 A mid-crestal incision can now be made, avoiding the fistula present to the buccal, with papillae-sparing incisions.

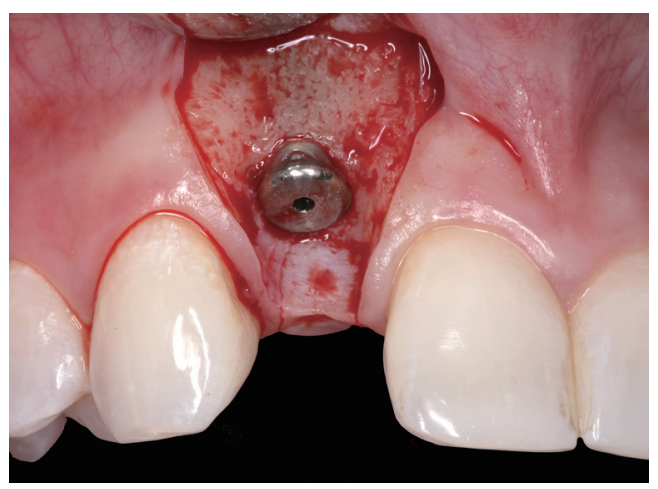

Figure 9 Note the presence of buccal plate and healthy interproximal bone levels around the fixture.

incisions can be extended beyond the mucogingival junction if the flap needs to be released to allow for greater coronal repositioning to accommodate passive primary closure around augmented sites along the principles of guided bone regeneration or soft tissue augmentation (10-12).

A papillae-sparing incision offers great advantage over a traditional intrasulcular incision in preserving esthetics and minimizing tissue trauma. The attachment apparatus in implants differs from that around teeth as peri-implant attachment is deprived of Sharpey's fibers and the blood supply associated with the periodontal ligament. Histologic studies on implants have documented collagen fibers in the connective tissue zone running parallel, versus perpendicular/oblique, to the implant surface, a lower

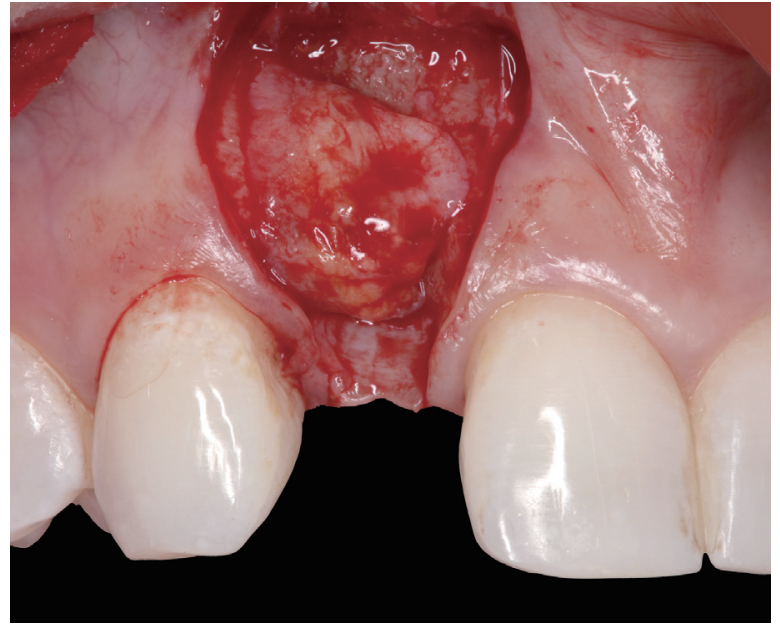

Figure 10 A full thickness bed is prepared to receive a CTG harvested from the palate. CTG, connective tissue grafting.

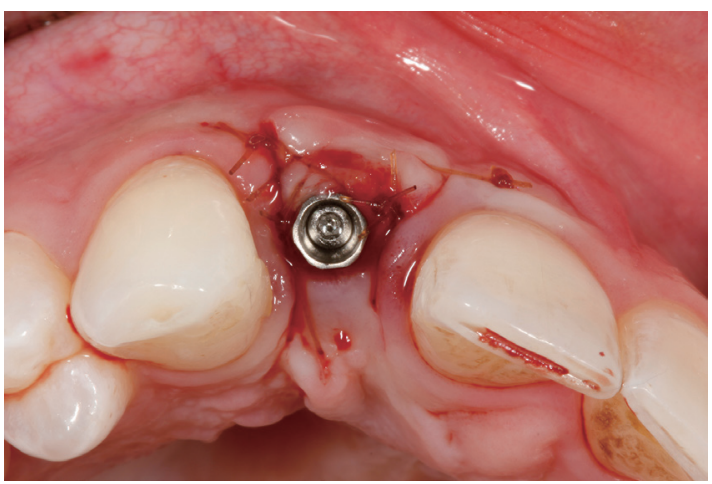

Figure 11 Three months after grafting, a papillae-sparing incision is made and a flat abutment is placed and allowed to heal for four more weeks before soft tissue sculpting with a new implantretained provisional.

number of fibroblasts, and a higher proportion of collagen $(13,14)$. Thus in the esthetic zone, the surgeon must be mindful to not disrupt the already compromised blood supply to this crucial interdental area as to preserve the interdental soft tissue architecture.

When the papillae are included in the elevation of a flap around a single implant, there is on average, $0.83 \mathrm{~mm}$ more interproximal bone loss after one year, as opposed to when they are not elevated (15). The papilla height on a single implant in the esthetic zone can be up to $4.5 \mathrm{~mm}$ in an apico-coronal direction (16). Therefore, the loss of almost $1 \mathrm{~mm}$ of supporting hard tissue can result in the collapse 


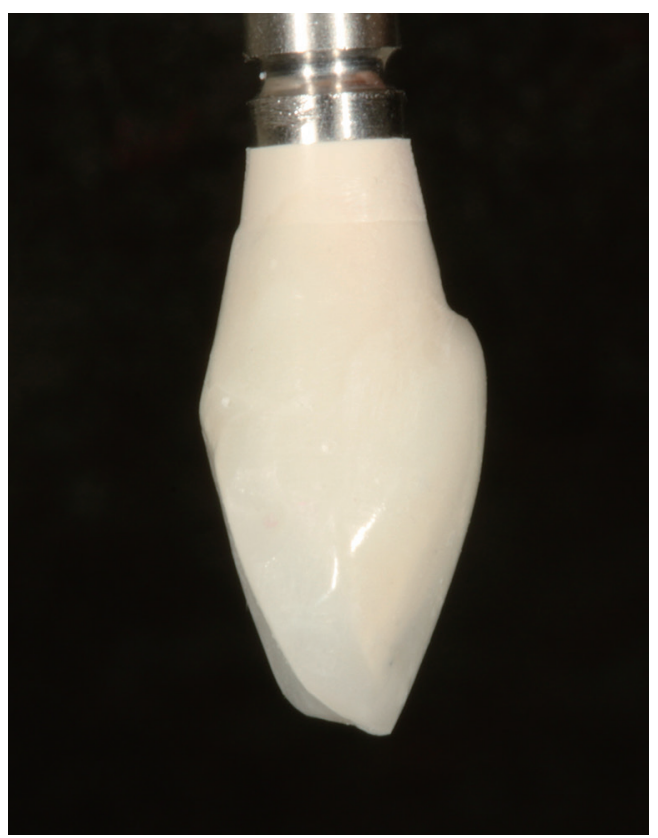

Figure 12 A flat contoured provisional is fabricated to support the new coronal tissue gain on the facial.

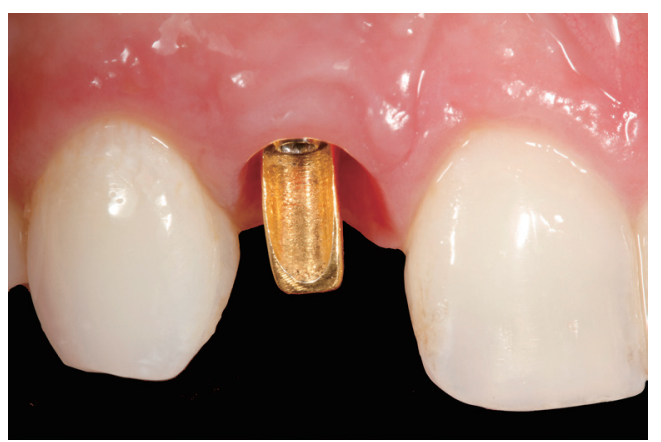

Figure 13 A custom gold-plated abutment is inserted with flat buccal contours.

of up to about a quarter of the dimension of the overlying papillae, drastically affecting the esthetics. In between adjacent implants, there is an average of $3-4 \mathrm{~mm}$ of papilla height (17), thus the soft and hard tissue resorptive effect if the papillae are disrupted is that much more drastic in these scenarios.

\section{Decoronation of the implant}

Decoronation as a method of soft tissue augmentation is a technique initially described by Langer (5) around teeth, allowing the clinician to gain an abundance of keratinized

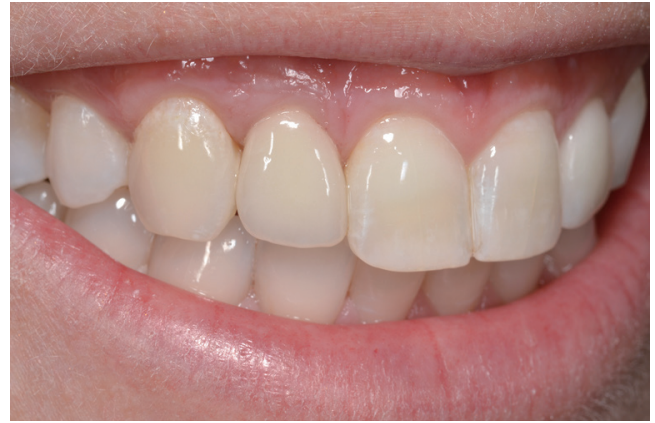

Figure 14 Definitive restoration in place. Note coronal tissue gained over the lateral incisor and no disturbance of the interdental papillae. Compare with Figure 2.

tissue (KT) via natural tissue creep ("nature's connective tissue graft"), facilitating flap management and improving vascularity for consequent site development procedures. Frequently, the clinician's inclination for addressing periimplant soft tissue defects is to treat the peri-implant defect like that around a tooth via typical root coverage procedures such as coronally advanced flaps with or without connective tissue grafting (CTG). However these techniques may prove to be more difficult as the vascular environment around implants is more compromised than that around teeth and healing relies solely on the blood supply from the alveolar bone and overlying flap. In addition, the implant surface can be typically contaminated with endotoxins, an environment that is not particularly conducive for wound healing.

When a decoronation technique is applied around implants, it allows for easier primary closure and thickening of tissue over the planned surgical site, optimizing wound healing potential and blood supply. Several studies have also intimated that a certain flap thickness can be a predictor for success of mucogingival correctional procedures $(18,19)$. When correcting mucogingival esthetic issues, negotiating the marginal gingiva is most important in terms of restoring acceptable esthetic soft tissue architecture. However, the marginal gingiva is the farthest from the base of the pedicle, whose blood supply travels in a caudo-cranial direction (20). Thus, a thicker flap will have better vascularization supply to ensure that the marginal gingiva has the optimal angiogenic environment for wound healing. Additionally this technique avoids the need for excessive flap manipulation and coronal advancement for ridge augmentation procedures, all of which can lead to distortion of the mucogingival junction, potentially creating a new esthetic issue and necessitating 


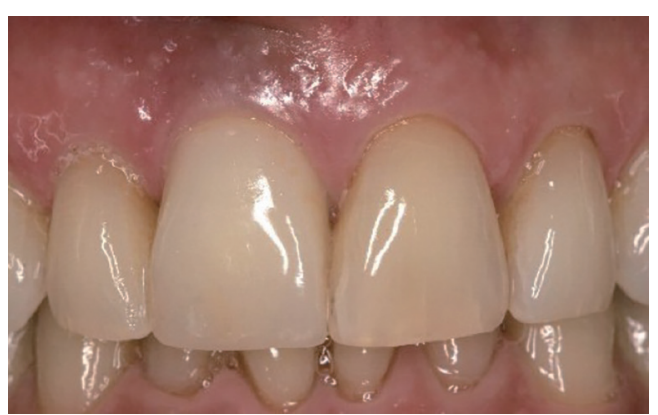

Figure 15 Preoperative view of implant in tooth \#8 position with a peri-implantitis bone defect but no soft tissue deformity.

a secondary procedure to apically position the tissue after healing.

\section{Soft tissue graft material}

In regards to soft tissue graft material, the question exists between autograft and allograft sources. Autogenous subepithelial CTG is still regarded as the gold standard in regards to recession coverage, clinical attachment gain, and increase in thickness of KT (21). Allograft acellular dermal matrices $(\mathrm{ADM})$ can be indicated in instances of augmenting multiple sites, where autogenous donor harvesting may not yield enough tissue for coverage of the recipient areas, or in the event of patient resistance to harvesting from a secondary surgical site. In general, ADM is successful in thickening the zone of attached tissue only; if the goal of therapy is to also gain additional KT, CTG is still the gold standard (22).

\section{Restoration contour}

In addition to surgical correction of esthetic deformities, the prosthetic aspect of the implant restoration must be addressed if it is contributing to peri-implant inflammation or if it can be modified to strategically allow for tissue stability long term. Restorative contours of fixed dental prostheses on teeth have been shown to have an impact on the periodontium, which can be either desired or undesired depending on the clinical situation and soft tissue phenotype (6). It has also been mentioned in the literature that over-contoured restorations can be a potential risk indicator for peri-implant disease (23).

The contour of the restoration can be utilized to manage the soft tissue profile, as described originally by Weisgold (6) on natural teeth, and also around implants (8). The critical contour of the restoration is that area which lies at the free gingival margin or $1 \mathrm{~mm}$ subgingival. The subcritical contour is the area apical to the critical contour, and exists as long as there is enough running room. Modifications to the critical and/or subcritical contour can aid in further tissue manipulation to achieve the desired result. An overcontoured subcritical zone tends to lead to increased recession. In cases of correcting soft tissue deficiencies, a flat or under-contoured subcritical contour can help to gain additional tissue coverage or maintain the level of the corrected free gingival margin.

\section{Working around the existing restoration}

Indications for working around the existing restoration or a healing abutment, instead of decoronation, would be the presence of an infrabony defect without any soft tissue deficiency in terms of recession or thickness. Treatment workflow would consist of peri-implantitis surgical treatment via a papillae-sparing approach, grafting, and replacement of the flap. Case scenario \#2 illustrates this such problem and management.

\section{Case scenario \#2}

Description of problem: peri-implantitis with sufficient soft tissue profile.

Abbreviated solution: decontamination of the implant surface via an open approach with papillae-sparing incisions for access. If the etiology of the peri-implantitis is cementtriggered (24), removal of cement is indicated. Hard tissue grafting is completed to fill the infrabony defect, followed by a repositioned flap.

The following case report illustrates an example of this case scenario. A 38 year-old Caucasian female presented with a chief complaint of gingival irritation around an implant in tooth \#8 position (Figure 15). Radiographic images show evidence of cement subgingivally on the distal aspect of the fixture (Figure 16), resulting in peri-implant bone loss and probe-able attachment loss (24) (Figure 17). An open flap approach of debridement was taken with papillae-sparing incisions as to not disturb the interdental tissue attachment on the implant (9). The cement was removed and the implant surface was mechanically debrided with a combination of curettage and irrigation (Figures 18,19). The defect was then grafted with mineralized cancellous allograft [Puros Allograft, Zimmer Biomet] and covered with a resorbable collagen membrane [Bio-Gide, Geistlich] (Figures 20,21). The flap was then repositioned and closed with several interrupted resorbable sutures (Figure 22). Four-year follow up demonstrates peri-implant health, resistance to probing at $3 \mathrm{~mm}$ and maintenance of esthetics of the fixture at position 


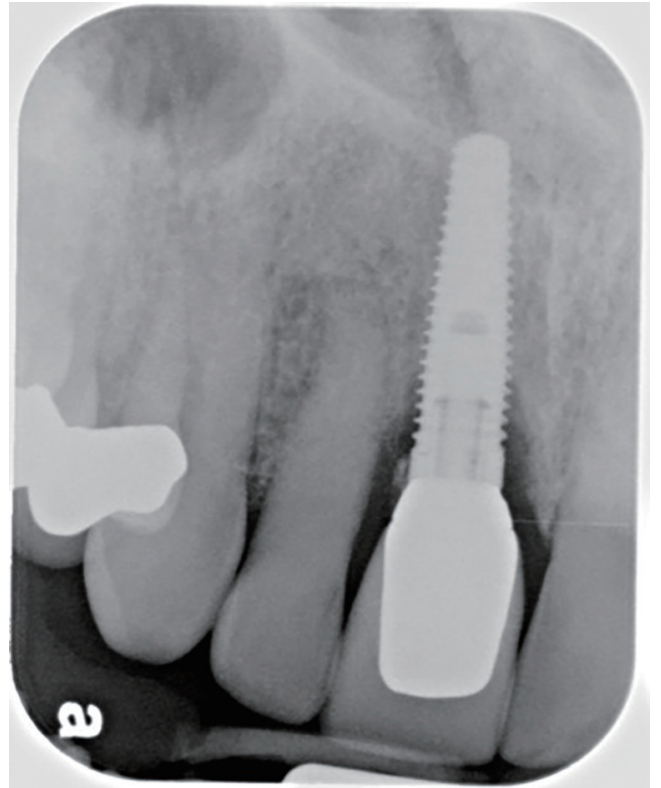

Figure 16 Note particle of cement on the distal aspect of the implant, contributing to peri-implant bone loss.

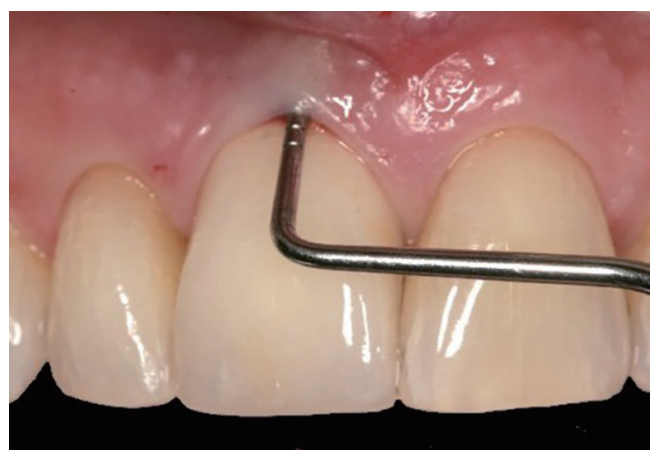

Figure 17 There is probe-able attachment loss due to periimplantitis.

\#8 and the adjacent natural teeth (Figure 23).

\section{Removal of cement}

Peri-implantitis may be caused by plaque or local plaqueretentive factors, such as subgingival cement. A prospective endoscopic study demonstrated that $81 \%$ of implants associated with peri-implant disease contained excess cement subgingivally (24). Furthermore, removal of the cement with an open flap approach resulted in resolution of the inflammation in $75 \%$ of the cases.

It has been suggested that corrosion and residual

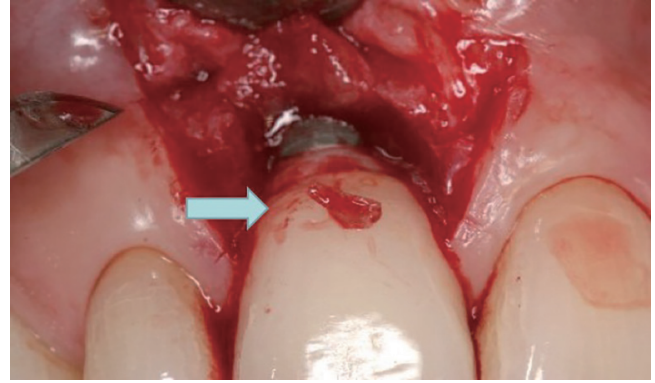

Figure 18 Note papillae-sparing incisions to preserve the gingival architecture and esthetics. A cement particle that was removed mechanically is displayed by the blue arrow.

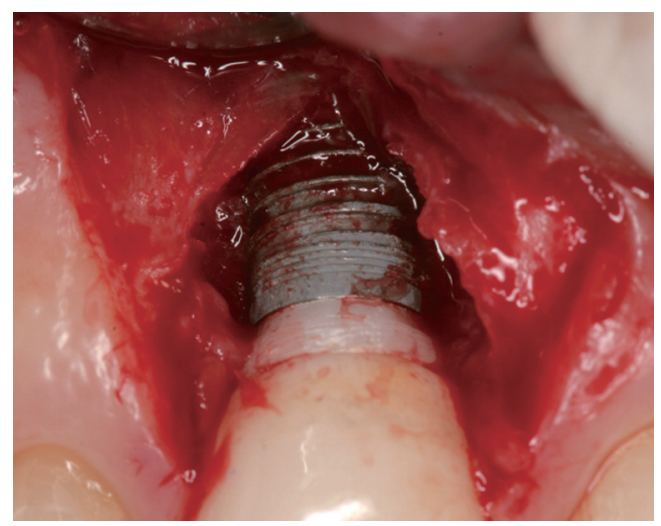

Figure 19 After mechanical debridement of the implant and removal of the cement, the area is ready to receive grafting.

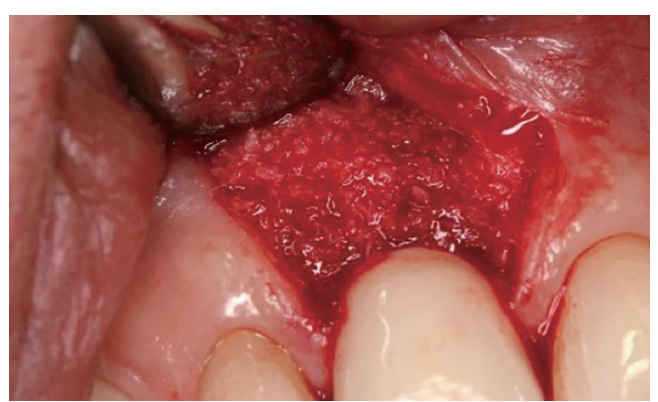

Figure 20 Cancellous allograft is placed and adapted around the decontaminated implant surface.

titanium particles from metal alloy abutment wear against the titanium surface of the implant can create a local macrophage response as well, in a type of secondary factor that can trigger peri-implantitis $(25,26)$. Regardless of the cause of peri-implantitis, the clinical manifestation 


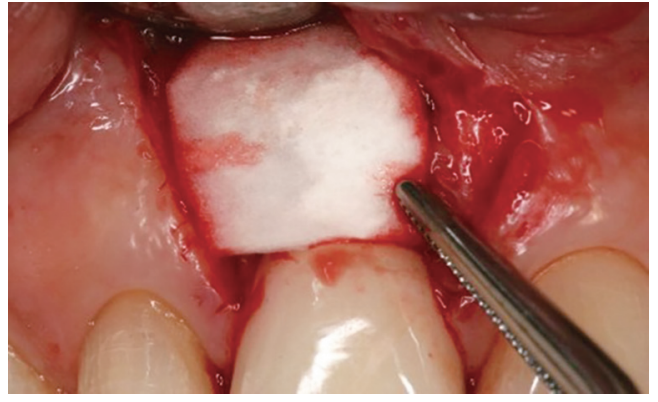

Figure 21 A collagen membrane is custom trimmed and placed on top of the bone graft.

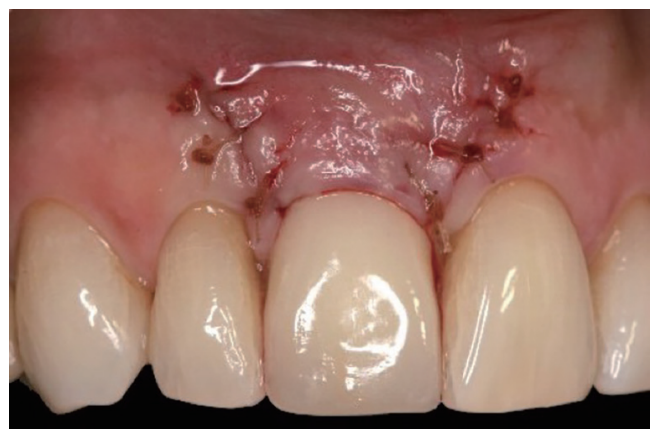

Figure 22 Several interrupted 5-0 chromic gut sutures are used to reposition the flap.

of disease activity can also ultimately depend upon the individual host response.

\section{Treatment approach: regenerative $v s$. resective, open} vs. closed

Goals of peri-implantitis therapy include but are not limited to: the removal of bacterial plaque within the peri-implant defect, the decontamination of the implant surface, and the regeneration of bone (27). There is controversy over whether an open versus closed debridement protocol is preferred to satisfy these end points, however one could extrapolate that the more apical the defect, the greater the need to adopt an open-flap approach in order to ensure comprehensive decontamination. The average curette efficiency limit for non-surgical therapy on a natural tooth is $3.73 \mathrm{~mm}$ (28). Implants in the esthetic zone usually are placed at least $3-4 \mathrm{~mm}$ apical to the mid-facial free gingival margin for optimal esthetics (29); additionally, the dimension of the papilla adds another $3-4 \mathrm{~mm}$ of depth interproximally (30). This depth already surpasses the efficiency limit for traditional curettage in a closed

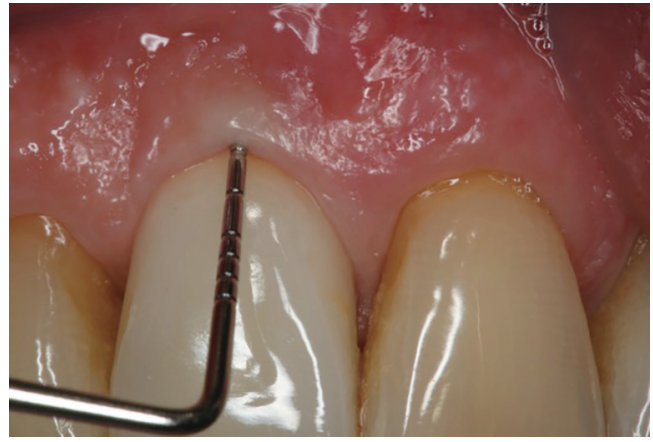

Figure 23 4-year follow-up. Note blanching of the tissue, which displays resistance to probing and re-establishment of a healthy peri-implant attachment apparatus.

approach, highlighting the advantages of an open flap protocol. Furthermore, the curette working stroke must be along the directional axis of the threads in a circumferential manner, further inhibiting the operator's range of instrument efficiency in a closed approach.

Implantoplasty has also been advocated as a possible therapeutic modality that could satisfy the goal of removal of biologic debris by complete removal of the threads and elimination of any micro-surface texture that harbors pathogens and plaque, facilitating oral hygiene. Implantoplasty along with resective surgery is typically indicated when there is a supracrestal defect present that is not amenable to regeneration; procedures are thus aimed at improving cleansability and oral hygiene for maintenance of the implant. A recently published protocol (31) advocates keeping the plastied portion of the implant supracrestal as the smoothened surface can facilitate soft tissue health. However, in the anterior zone, this is not a viable option as it would create an esthetically unacceptable result with the plastied implant visible.

\section{Decontamination of the implant surface}

Implants can be decontaminated via chemical debridement, manual debridement, or laser debridement. Chemical debridement may include irrigants such as saline, chlorhexidine, hydrogen peroxide, phosphoric acid gel, tetracycline, diluted bleach, and citric acid. Mechanical methods of debridement include curettage, titanium brush usage, application of micro-abrasive powders, and implantoplasty $(32,33)$. Despite all of these various forms of decontamination, there is no one consensus on a superior form of peri-implant decontamination within the current literature (34). 
Concerning closed laser debridement, the best evidence consensus on laser therapy (35) concluded that outcomes of lasers as a monotherapy could not be evaluated as no controlled studies were identified within the literature. However, as an adjunct to surgical or non-surgical therapy, lasers can be of modest benefit in regard to probing depth reduction, clinical attachment level gain, and amount of recession improvement. A recent short term randomized controlled clinical trial compared the efficacy of Er:YAG laser debridement in conjunction with mechanical debridement versus mechanical debridement alone in guided bone regeneration surgical treatment of infrabony periimplantitis lesions (36). The laser group produced better results that were statistically, but not clinically, significant in terms of clinical attachment level gain and gingival index improvement. The authors concluded that in the short term (up to 6 months), Er:YAG debridement as an adjunct to open flap mechanical debridement and guided bone regeneration could provide some improvement in probing depth reduction (less than $1 \mathrm{~mm}$ ) in the treatment of infrabony peri-implant lesions. However, more randomized controlled clinical trials with longer term follow-up and larger sample size are needed to more adequately conclude the efficacy of surgical laser therapy of peri-implantitis.

\section{Hard tissue graft material}

Re-osseointegration to previously infected implant surfaces is not a reliably reproducible biologic phenomenon and has been sparsely documented in the literature in human subjects $(33,37)$. As such, the goal of therapy should instead be targeted at elimination of the pathologic etiology responsible for the peri-implant disease and reconstruction of the hard and soft tissue esthetic defect. There exists a myriad of hard tissue allograft, xenograft, or alloplast materials available today on the market, all with varying capabilities of osteo-induction or -conduction. Osteogenic potential is possible if using autogenous sources, whether in the form of harvested bone or platelet rich plasma/fibrin (38). The material of choice is dependent upon the desired end goal of therapy and what properties the clinician wishes to utilize for such. A xenograft material can provide excellent space maintenance and contour stability over time due to a slower resorption rate of the graft particulate (39). However, if vital bone replacement is the goal, the clinician may consider an allograft substitute $(40,41)$. As re-osseointegration of the implant is not a reliable goal of therapy, typically using a xenograft material that can provide space maintenance over time will allow for the best long-term contour stability of the reconstructed defect.

\section{When to treat the existing implant or remove and place a new implant}

There are two different scenarios of peri-implantitisinduced hard tissue loss within the esthetic zone: a hard tissue defect in combination with an esthetic deformity or without an esthetic deformity. Case scenario \#2 illustrates the classification and management of the latter situation. However, in the former situation, the goals of therapy are the following: to gain bone fill on a contaminated implant surface, graft soft tissue over, and potentially regrow the papillae if lost. In these cases, the biological ask of the host response may be too great of an onus for a predictable clinical outcome; thus it is recommended to remove the implant and rebuild the site. Situations like this could be due to excessive labial angulation or problematic apicocoronal spatial placement of the fixture (i.e., too shallow placement) in addition to peri-implant disease. Case scenario \#3 illustrates this such situation.

\section{Case scenario \#3}

Description of problem: peri-implantitis with accompanying esthetic deformities.

Abbreviated solution: explantation of the implant, followed by site development for a future implant replacement.

The following case report illustrates a typical scenario that would contraindicate attempting to save or repair the existing implant. A 60-year old Caucasian female presented with a chief complaint of missing papillae between preexisting implants in the \#9 and \#10 positions (Figure 24). The two implants had pre-existing bone loss and interproximal soft tissue collapse (Figure 25). As such, the surgical goals of therapy are to regenerate the bone loss on the fixtures along with the interproximal papillae. As the vertical soft tissue dimensions on adjacent implants are more limited $(16,17)$, attempts to regenerate soft tissue that would be esthetically acceptable on unhealthy and decontaminated surfaces is too great a biologic ask of the host for a predictable result. Thus often times, the use of pink porcelain may be a more direct solution in these situations. An exhaustive explanation of this type of situation would be beyond the scope of this article as there can be any permutation of variables that may inform the treatment planning decision making process for remediation of these complex cases. However, in general in such a situation, the 


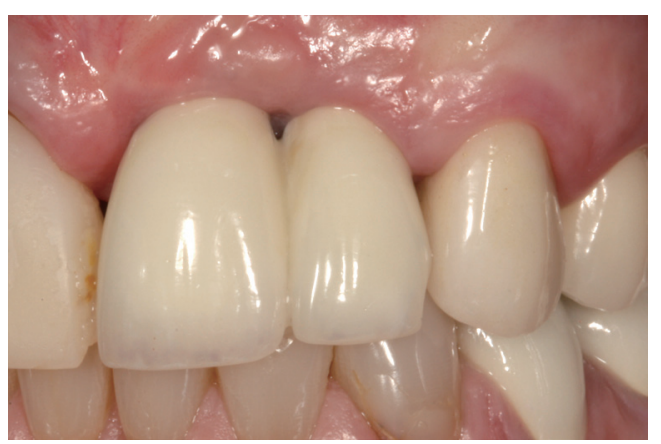

Figure 24 Patient presents with a two-unit fixed implant supported prosthesis on implants in tooth positions \#9 and \#10. There is pre-existing bone loss and soft tissue collapse of the peri-implant tissues on both fixtures.

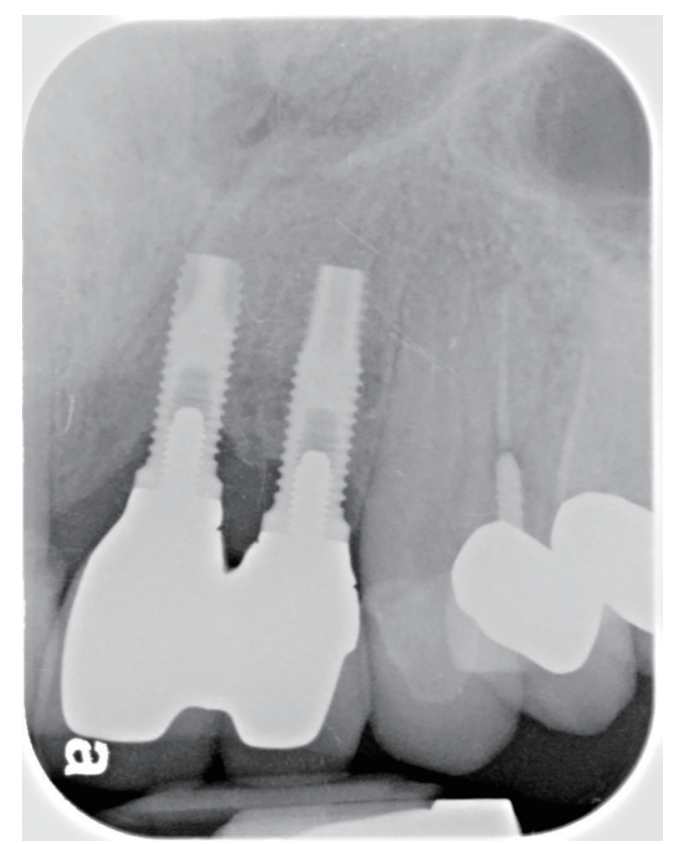

Figure 25 Note the pre-existing interproximal bone loss on both fixtures.

authors recommend explantation and reconstruction of the site for a future implant placement in a strategic position.

\section{Conclusions}

Peri-implantitis in the esthetic zone is a challenging problem to treat effectively and requires proper diagnosis and management of a multitude of factors. Identification and understanding of the etiology of the type of hard and soft tissue peri-implant defects determines the treatment workflow and deciding whether to save or remove the affected implants. Proper diagnosis and attention to detail can help avoid creating future esthetic problems and assist in achieving desired clinical outcomes.

\section{Acknowledgments}

Funding: None.

\section{Footnote}

Provenance and Peer Review: This article was commissioned by the Guest Editor (Ole T. Jensen) for the series "Current Advances in Treatment of Peri-Implantitis" published in Frontiers of Oral and Maxillofacial Medicine. The article has undergone external peer review.

Reporting Checklist: The authors have completed the RIGHT reporting checklist. Available at https://fomm. amegroups.com/article/view/10.21037/fomm-21-59/rc

Conflicts of Interest: All authors have completed the ICMJE uniform disclosure form (available at https://fomm. amegroups.com/article/view/10.21037/fomm-21-59/ coif). The series "Current Advances in Treatment of PeriImplantitis" was commissioned by the editorial office without any funding or sponsorship. The authors have no other conflicts of interest to declare.

Ethical Statement: The authors are accountable for all aspects of the work in ensuring that questions related to the accuracy or integrity of any part of the work are appropriately investigated and resolved.

Open Access Statement: This is an Open Access article distributed in accordance with the Creative Commons Attribution-NonCommercial-NoDerivs 4.0 International License (CC BY-NC-ND 4.0), which permits the noncommercial replication and distribution of the article with the strict proviso that no changes or edits are made and the original work is properly cited (including links to both the formal publication through the relevant DOI and the license). See: https://creativecommons.org/licenses/by-nc-nd/4.0/.

\section{References}

1. Elani HW, Starr JR, Da Silva JD, et al. Trends in Dental 
Implant Use in the U.S., 1999-2016, and Projections to 2026. J Dent Res 2018;97:1424-30.

2. Derks J, Schaller D, Håkansson J, et al. Effectiveness of Implant Therapy Analyzed in a Swedish Population: Prevalence of Peri-implantitis. J Dent Res 2016;95:43-9.

3. Koldsland OC, Scheie AA, Aass AM. Prevalence of periimplantitis related to severity of the disease with different degrees of bone loss. J Periodontol 2010;81:231-8.

4. Renvert S, Persson GR, Pirih FQ, et al. Peri-implant health, peri-implant mucositis, and peri-implantitis: Case definitions and diagnostic considerations. J Periodontol 2018;89 Suppl 1:S304-12.

5. Langer B. Spontaneous in situ gingival augmentation. Int J Periodontics Restorative Dent 1994;14:524-35.

6. Weisgold AS. Contours of the full crown restoration. Alpha Omegan 1977;70:77-89.

7. Chu SJ, Tarnow DP. Managing esthetic challenges with anterior implants. Part 1: midfacial recession defects from etiology to resolution. Compend Contin Educ Dent 2013;34 Spec No 7:26-31.

8. Su H, Gonzalez-Martin O, Weisgold A, et al. Considerations of implant abutment and crown contour: critical contour and subcritical contour. Int J Periodontics Restorative Dent 2010;30:335-43.

9. Greenstein $\mathrm{G}$, Tarnow D. Using papillae-sparing incisions in the esthetic zone to restore form and function. Compend Contin Educ Dent 2014;35:315-22.

10. Greenstein G, Greenstein B, Cavallaro J, et al. Flap advancement: practical techniques to attain tension-free primary closure. J Periodontol 2009;80:4-15.

11. Wang HL, Boyapati L. "PASS" principles for predictable bone regeneration. Implant Dent 2006;15:8-17.

12. Pini Prato GP, Baldi C, Nieri M, et al. Coronally advanced flap: the post-surgical position of the gingival margin is an important factor for achieving complete root coverage. J Periodontol 2005;76:713-22.

13. Berglundh T, Lindhe J, Ericsson I, et al. The soft tissue barrier at implants and teeth. Clin Oral Implants Res 1991;2:81-90.

14. Araujo MG, Lindhe J. Peri-implant health. J Periodontol 2018;89 Suppl 1:S249-56.

15. Gomez-Roman G. Influence of flap design on periimplant interproximal crestal bone loss around single-tooth implants. Int J Oral Maxillofac Implants 2001;16:61-7.

16. Salama M, Ishikawa T, Salama H, et al. Advantages of the root submergence technique for pontic site development in esthetic implant therapy. Int J Periodontics Restorative
Dent 2007;27:521-7.

17. Tarnow D, Elian N, Fletcher P, et al. Vertical distance from the crest of bone to the height of the interproximal papilla between adjacent implants. J Periodontol 2003;74:1785-8.

18. Baldi C, Pini-Prato G, Pagliaro U, et al. Coronally advanced flap procedure for root coverage. Is flap thickness a relevant predictor to achieve root coverage? A 19-case series. J Periodontol 1999;70:1077-84.

19. Huang LH, Neiva RE, Wang HL. Factors affecting the outcomes of coronally advanced flap root coverage procedure. J Periodontol 2005;76:1729-34.

20. Mörmann W, Ciancio SG. Blood supply of human gingiva following periodontal surgery. A fluorescein angiographic study. J Periodontol 1977;48:681-92.

21. Chambrone L, Tatakis DN. Periodontal soft tissue root coverage procedures: a systematic review from the AAP Regeneration Workshop. J Periodontol 2015;86:S8-51.

22. Leong DJ, Wang HL. A decision tree for soft tissue grafting. Int J Periodontics Restorative Dent 2011;31:307-13.

23. Katafuchi M, Weinstein BF, Leroux BG, et al. Restoration contour is a risk indicator for peri-implantitis: A crosssectional radiographic analysis. J Clin Periodontol 2018;45:225-32.

24. Wilson TG Jr. The positive relationship between excess cement and peri-implant disease: a prospective clinical endoscopic study. J Periodontol 2009;80:1388-92.

25. Mouhyi J, Dohan Ehrenfest DM, Albrektsson T. The peri-implantitis: implant surfaces, microstructure, and physicochemical aspects. Clin Implant Dent Relat Res 2012;14:170-83.

26. Olmedo D, Fernández MM, Guglielmotti MB, et al. Macrophages related to dental implant failure. Implant Dent 2003;12:75-80.

27. Mombelli A. Microbiology and antimicrobial therapy of peri-implantitis. Periodontol 2000 2002;28:177-89.

28. Stambaugh RV, Dragoo M, Smith DM, et al. The limits of subgingival scaling. Int J Periodontics Restorative Dent 1981;1:30-41.

29. Chu SJ, Salama MA, Salama H, et al. The dual-zone therapeutic concept of managing immediate implant placement and provisional restoration in anterior extraction sockets. Compend Contin Educ Dent 2012;33:524-32, 534.

30. Choquet V, Hermans M, Adriaenssens P, et al. Clinical and radiographic evaluation of the papilla level adjacent to single-tooth dental implants. A retrospective study in the maxillary anterior region. J Periodontol 2001;72:1364-71. 
31. Sinjab K, Garaicoa-Pazmino C, Wang HL. Decision Making for Management of Periimplant Diseases. Implant Dent 2018;27:276-81.

32. Zablotsky MH, Diedrich DL, Meffert RM. Detoxification of endotoxin-contaminated titanium and hydroxyapatitecoated surfaces utilizing various chemotherapeutic and mechanical modalities. Implant Dent 1992;1:154-8.

33. Fletcher P, Deluiz D, Tinoco EM, et al. Human Histologic Evidence of Reosseointegration Around an Implant Affected with Peri-implantitis Following Decontamination with Sterile Saline and Antiseptics: A Case History Report. Int J Periodontics Restorative Dent 2017;37:499-508.

34. Heitz-Mayfield LJ, Mombelli A. The therapy of periimplantitis: a systematic review. Int J Oral Maxillofac Implants 2014;29 Suppl:325-45.

35. Lin GH, Suárez López Del Amo F, Wang HL. Laser therapy for treatment of peri-implant mucositis and periimplantitis: An American Academy of Periodontology best evidence review. J Periodontol 2018;89:766-82.

36. Wang CW, Ashnagar S, Gianfilippo RD, et al. Laserassisted regenerative surgical therapy for peri-implantitis:

doi: 10.21037/fomm-21-59

Cite this article as: Tarnow DP, Chu SM, Chu SJ. Periimplantitis in the esthetic zone: a guideline for decision making and treatment modalities. Front Oral Maxillofac Med 2021;3:22.
A randomized controlled clinical trial. J Periodontol 2021;92:378-88.

37. Renvert S, Polyzois I, Maguire R. Re-osseointegration on previously contaminated surfaces: a systematic review. Clin Oral Implants Res 2009;20 Suppl 4:216-27.

38. Miron RJ, Zucchelli G, Pikos MA, et al. Use of plateletrich fibrin in regenerative dentistry: a systematic review. Clin Oral Investig 2017;21:1913-27.

39. Chappuis V, Rahman L, Buser R, et al. Effectiveness of Contour Augmentation with Guided Bone Regeneration: 10-Year Results. J Dent Res 2018;97:266-74.

40. Froum SJ, Wallace SS, Elian N, et al. Comparison of mineralized cancellous bone allograft (Puros) and anorganic bovine bone matrix (Bio-Oss) for sinus augmentation: histomorphometry at 26 to 32 weeks after grafting. Int J Periodontics Restorative Dent 2006;26:543-51.

41. Xavier SP, Dias RR, Sehn FP, et al. Maxillary sinus grafting with autograft vs. fresh frozen allograft: a splitmouth histomorphometric study. Clin Oral Implants Res 2015;26:1080-5. 